\title{
Procesos cognitivos: una introducción a la psicología informacional
}

\section{José María Tous Ral*}

\author{
Universidad de Barcelona
}

Jerry A. Fodor, en su ensayo sobre la psicologia de las facultades, titulado: $L a$ modulación de la mente (1983), nos dice en los «agradecimientos», que la «escolarización es el proceso por el cual las mariposas se transforman en gusanos». He querido recoger estas palabras de Fodor para iniciar mi exposición aquí, porque si no describen con toda exactitud lo que sentimos algunos profesores y casi todos los alumnos cada día en clase, son adecuadas a la espontaneidad, entusiasmo y capacidad de trabajo de los estudiantes que habéis organizado estas jornadas ${ }^{1}$.

Todo el mundo habla, debe ser el espiritu de los tiempos, de procesos, de mecanismos, de funciones, de estructuras... Martín Navarro, autor del primer Manual de Psicologia Experimental, publicado en España, concretamente en Tarragona el año 1914, al referirse a las grandes corrientes del pensamiento humano a través de la historia, introduce el concepto de «Hipótesis Dominante». En todas las épocas, como motor de lo que el análisis kuhniano llamó «revoluciones científicas", surge y se consolida una hipótesis que no es más que una forma de explicación nueva de la realidad. Esta hipótesis cuando está presente en todas las ciencias, por diferentes que sean sus respectivos objetos de estủdio, podemos considerarla dominante. Todos hablamos de procesos, de mecanismos, de funciones, de estructuras; pero, sólo, atendiendo a cuál es la hipótesis dominante de esta época, podremos elaborar una delimitación precisa de estos términos.

El núcleo de la hipótesis dominante actual lo constituye el concepto de información. Wiener, ya en la década de los años cuarenta, dijo que la realidad no podía explicarse atendiendo, tan sólo, a los conceptos de materia y energia, sino que era necesario tomar en consideración el concepto de información. La historia de la introducción del concepto de información en la psicología no es el objetivo

* Dirección del autor: Departamento de Psicología Experimental. Facultad de Filosofia de Tarragona, Universidad de Barcelona (Tarragona).

1 Este articulo recoge la aportación de J. M. Tous a las jornadas de Psicologia organizadas por los estudiantes de la Universidad de Oviedo en 1984. 
de este trabajo, tan sólo señalaré que George A. Miller (1960) definió la infor-. mación como «la reducción de la incertidumbre asociada con el estado de una situación particulary. Hay dos aspectos que debemos resaltar de esta delimitación:

1..$^{\circ}$ La reducción de la incertidumbre, como dice Mahoney (1974), no depende sólo del input, sino que es el resultado de la interacción del input y su utilización por parte del que lo detecta percibiéndolo.

2. ${ }^{\circ}$ La analogia implícita entre el concepto de entropía, propuesto por Clausius (1859-1865) - según el cual la entropía del universo tiende a crecer con cada variación de estado de un cuerpo fisico, para llegar a su máximo en el cero absoluto-, y el concepto de incertidumbre asociada con el estado de una estructura - según el cual la incertidumbre manifiesta el nivel de orden u organización interna de la misma, tendente a aumentar hasta destruirse.

Ya que el modo mediante el cual la forma de una estructura, o su nivel de organización interna, puede evitar la destrucción, o lo que es lo mismo, mantenerse a un determinado nivel de incertidumbre, consiste en su capacidad de intercambiar información, vamos a plantear la psicología cognitiva basada en el procesamiento de información desde este enfoque.

Es muy posible que el lector de psicologia cognitiva se lleve una decepción al constatar que los planteamientos de esta psicología no se enfrentan directamente con todo aquello que entendemos por ser humano, sino que tan sólo se ocupan de los procesos sensoriales, perceptuales y mnémicos del mismo, olvidando los procesos energéticos de emoción y motivación que, atendiendo a la validez ecológica de las teorías, deberían estar en la base de los primeros. Otra decepción que se lleva el lector de psicología cognitiva y que va en aumento en los estudiantes universitarios de psicologia, es la visión poco científica que proporcio- nan algunos de los autores en este campo. En la actualidad, se acepta que la ciencia es acumulativa y, por consiguiente, los planteamientos que llevan a comenzar de nuevo no constituyen el camino propio de la ciencia. Esto no significa que en la ciencia no se den revoluciones en el sentido kuhniano, pero la pervivencia de éstas se basa en su capacidad de explicar los fenómenos anteriores $y$, además, aquellos que antes no podían siquiera ser planteados.

Sorprende que Neisser (1967) nos diga que «términos tales: como sensación, percepción, imaginación, recuerdo, solución de problemas y pensamiento, entre otros, se refieren a etapas o aspectos hipotéticos de la cognición", y que más adelante señale: "de hecho, los propios teóricos del estímulo-respuesta están inventando mecanismos hipotéticos con vigor $y$ entusiasmo y con pocos remordimientos de conciencias. Si tan sólo hojeamos la historia de la psicología veremos que en 1967 hacía más de treinta años que los constructos hipotéticos, entendidos como variables intermediarias, estaban presentes en la psicología del neoconductismo o del llamado estimulorespuesta.

No es menor la sorpresa al leer la obra de Lachman, Lachman y Butterfield (1979) en la cual no aparece como aportación al cognitivismo la aceptación de procesos internos entre el estímulo y la respuesta por parte del neoconductismo o neoasociacionismo.

Evidentemente, como ya señalé en $\mathrm{mi}$ libro: Psicologia Experimental (1978), es necesario distinguir entre los constructos hipotéticos del neoconductismo y los términos de sobresignificado, que a veces ha utilizado el cognitivismo. Una distinción es la que propone Arnau (1982) al comentar a Ackoff (1973) en el sentido que los constructos hipotéticos del neoconductismo se deben considerar como propios de la edad del mecanicismo, mientras que los constructos hipotéticos de la psicología cognitiva, se deben considerar como propios de la edad de 
los sistemas. Otra distinción es la que proponemos nosotros entre constructos hipotéticos que describen procesos seriales y constructos hipotéticos que describen procesos de control (Hintzman, 1978). Tanto un tipo como otro de proceso es mecanicista y buena prueba de ello la tenemos en la automatización. La teoria general de sistemas carece de sentido si olvidamos que un sistema es un mecanismo de regulación o de control por retroalimentación. Por lo que consideramos que así como el nivel energético de la conducta estaba presente en los constructos hipotéticos del neoconductismo - la pulsión en Woodworth y Tolman, la motivación en Hull y Spencer-, también está presente en los mecanismos de control que sustenta la teoría de sistemas; mientras que en el modo como la psicología cognitiva ha utilizado el procesamiento de información no aparece, ni de forma explícita, ni implícita el nivel energético de la conducta.

En la presente exposición nosotros defendemos que los mecanismos que organizan la conducta tienen una importancia tan grande como la energía misma en la determinación de aquélla, que estos mecanismos son tanto seriales como de control y que los estadios de procesamiento de información deben corresponder en su naturaleza a estos mecanismos. Estamos, por consiguiente, tan de acuerdo en que el neoconductismo sin la cibernética, desembocó en un situacionismo, como en que la psicología cognitiva no ha pasado de ser un neomentalismo, basado en la metáfora mente-ordenador que la simulación sin base en la cibernética ha puesto de moda.

Después de esta introducción, vamos a centrar la exposición en el tema de la información desde dos contextos diferen-. tes, que intentaré relacionar:

1. El contexto de la comunicación, en especial la comunicación humana.

2. El contexto de la cibernética y la teoría de sistemas, sustentando la proposición de Boulanger (1981) de que la teo- ría de sistemas constituye una parte de la cibernética y no al revés.

\section{LA INFORMACION DESDE LA COMUNICACION}

Una forma de plantear el tema de la información consiste en enmarcarla en el contexto de la comunicación humana. Como dijo C. Cherry (1956) la comunicación es un hecho esencialmente social $y$, aunque parece bastante obvio que al comunicarnos pretendemos dar o recibir información, debemos distinguir entre comunicación e información. Una primera distinción la podemos fundar en la afirmación realizada por Mahoney (1974), de que la información no necesita involucrar, necesariamente, procesos mentales superiores ni la conciencia para darse, mientras que todos estaremos de acuerdo en que la comunicación humana implica símbolos $\mathrm{y}$, por consiguiente, un código que para utilizarse necesita de procesos mentales superiores.

Con todo, también, hablamos de comunicación no verbal entre humanos e incluso de comunicación animal (Remesar, Riba, Rodríguez, 1982), a pesar de que en estos casos no se ven implicados los símbolos. Parece, por tanto, necesario considerar la información que procede de un signo o señal de aquélla que procede de un símbolo. Es de todos conocido que fisicamente al comunicar se transmiten signos o señales visuales, audibles o táctiles, pero que esto por sí solo, no constituye la comunicación. Sólo se da comunicación si aquel signo o señal tiene potencial para seleccionar la respuesta del receptor. Por esto, la teoría de la comunicación tiene, como objeto de estudio, la medida del contenido de información de un signo o señal en el establecimiento de lazos de comunicación, o sea, la propiedad' del mismo para evocar la respuesta selectiva del receptor.

Tenemos, pues, que al hablar de un signo o señal deberemos distinguir entre la propiedad fisica del mismo y la medida de esta propiedad. Cherry, al respec- 


\section{6}

to, nos dice: «las palabras no son cosas significativas en una relación una a una como en un código. Las palabras son, también, signos o señales empíricos y no sólo representaciones o modelos de algo (símbolos)». De esta posición, podemos concluir que un signo o señal es aquello que está presente de forma material y tiene la capacidad de desencadenar una conducta en la persona que se convierte en receptor de la misma. Hay palabras que al oírlas son señal de que el emisor es tartamudo, hay palabras que al ser leidas son señal de una ortografia incorrecta, e incluso hay palabras que son señal de que quien la utiliza no conoce su significado en el diccionario. Además, una palabra, al igual que cualquier otra cosa real y material, también puede ser un signo. Las palabras son signos cuando tienen un significado por convención, pero este significado convencional no agota toda su posibilidad de información significativa, como hemos visto.

Al hablar de significado, no podemos dejar de mencionar la distinción realizada por Osgood (1957) entre significado denotativo y connotativo. Hay palabras más denotativas que otras, por cuanto nos sirven para acceder a las cosas nombradas sin ninguna vaguedad o error (ejemplo, el nombre de una persona, la matrícula de un coche). En cambio, hay otras palabras que no son puramente denotativas y son aquéllas que responden a un propósito de clasificación (ejemplo, grande, redondo), ya que, a pesar de su significado denotativo, se aplican a objetos muy diferentes, por lo que no denotan específicamente a ninguno de ellos. Así, también, los nombres comunes al no referir a cosas particulares sino a clases de cosas. Por último, palabras como democracia, civilización y educación que tienen distinto significado para diferentes clases de personas y palabras como libertad, belleza, progreso, cambio que significan cosas distintas para distintas personas.

Las palabras no son, pues, simplemente signos empíricos que se refieren a un significado convencional, ya que la des-

\section{Estudios}

cripción en otras palabras de un vocablo no constituye una definición de la misma en su sentido lógico o científico, sino histórico y cultural, o sea, por su uso y por las condiciones específicas de este uso (Tous y Vallejo, 1981). Por consiguiente, una palabra no es un símbolo por su potencial significativo como señal o como signo, sino por la posibilidad de ser utilizada sin estar ella misma presente de forma material.

Con todo, la comunicación humana no se realiza sólo con palabras, sino con un hablante y un oyente, por lo menos, con unas expresiones faciales y unos gestos como hemos dicho, y en particular mediante un lenguaje. Podemos considetar el lenguaje desde un punto de vista material o físico $y$, también, desde un punto de vista lingüístico o abstracto. En el primer caso, el lenguaje consiste en un cuerpo completo de todas las expresiones realizadas por un grupo especifico de personas durante un período concreto. En el segundo caso, se considera como una colección o conjunto de hábitos - reflejos nos dirá Merril Garrett (1983)-, descritos como una serie de signos y leyes. En base a esta distinción, tanto los aspectos físicos como lingüísticos del lenguaje confieren a éste la capacidad de creación de nuevas palabras y determinan el significado de las mismas.

El problema del significado fue planteado por Peirce (1931-35) mediante un triángulo en que en cada vértice aparecía o el pensamiento, o la cosa designada, o la palabra. Este modelo lo tomaron posteriormente Ogden y Richards (1949), los cuales especificaron que el lado constituido por palabra/cosa designada no implica relación causal alguna, mientras que los lados del triángulo comprendidos entre cosa designada/pensamiento y palabra/pensamiento sí implican relación causal. Cherry (1957) hace una nueva adaptación de este modelo al considerar que las relaciones que se representan por cada lado del triángulo manifiestan procesos perceptuales o procesos de asociación, gracias a la memoria del sujeto. De 


\section{Estudios}

esta forma la relación entre la cosa designada y el pensamiento es una relación perceptual, al igual que la relación entre el pensamiento y la palabra, pero la relación entre la palabra y la cosa designada es una asociación. La memoria pasa a sustituir al pensamiento por cuanto en las anteriores aproximaciones al modelo que estamos considerando el pensamiento se consideraba como el nivel de conocimientos. Tanto en la tesis doctoral del profesor Vallejo como en la tesis de licenciatura de Pilar González (1983 y 1984) es fácil constatar a nivel empírico y bibliográfico, respectivamente, que el contenido de la memoria no es más que el nivel de conocimientos disponibles por el sujeto.

Resulta bastante obvio considerar que la cosa designada puede ser distinta respecto al signo o señal utilizado por cada comunicante o emisor por diferente clase de asociación, por lo que la percepción de la señal o signo podría no ser la misma que la percepción de la cosa referida de no funcionar la memoria como un común denominador de estas relaciones, consideramos entonces que el significado tanto procedente de la sintaxis como de la semántica es la información que permite seleccionar la respuesta, pero la comunicación no es por sí misma información, se trata tan sólo que la información puede ser comunicada gracias a la presencia de los niveles sintáctico y semántico. ¿Pero qué clase de información puede ser comunicada? La palabra información se utiliza en muy diferentes sentidos, así veremos que se habla de información útil, de información estimable, de información factual, de información confiable, de información virtual (Ciplea, 1982)..., pero ninguna de estas expresiones aparece en la teoría estadística de la comunicación que describe la información únicamente como una rareza estadística desde una fuente de observación.

La teoría estadística de la comunicación se refiere a la información en el nivel meramente sintáctico, o sea aquel en el que se dan los signos o señales y las relaciones entre los mismos. La presencia de información en el nivel sintáctico reduce la incertidumbre a medida que el estado sensorial facilita la discriminación entre la presencia de ruido sólo o de señal más ruido (TDS). Esta afirmación se constata al comprobar que entonces la decisión en responder sí o no es mayor. Pero en general, y concretamente en psicología, al hablar de información nos referimos casi siempre al nivel de los designata, o sea que el tema de la información se considera más a nivel semántico que sintáctico.

En el nivel semántico podemos observar que una misma comunicación nos proporciona generalmente dos tipos de información: «este comercio cierra los domingos» informa, además, que aquel comercio «está abierto el resto de los dias de la semana». Estas dos informaciones presentes en una sola comunicación parecen corresponder a la distinción realizada por Quine entre teoria del significado y teoría de la referencia. La primera información corresponde al significado de la proposición, mientras que la segunda información corresponde al contexto referencial de la proposición. Es fácil constatar, entonces, que el nivel semántico considerado tan sólo como teoría del significado no reduce la incertidumbre, ya que para conseguirlo debe ir acompañado de la teoría de la referencia o contexto social.

También es posible considerar la información en el nivel pragmático. Un ejemplo lo encontramos cuando utilizamos referencias en nuestro trabajo de comunicación. En estos casos, la referencia tiene también la capacidad de proporcionar diferentes informaciones. Para algunos receptores será un argumento de autoridad, para otros será un dato a consultar y para unos pocos ayudará a evocar algo que está en su memoria. Evidentemente, la información en el nivel pragmático tan sólo reducirá la incertidumbre cuando la referencia sirva para recordar algo ya conocido. Esta consideración exige que en la selección de respuesta del emisor se intente la adecuación de la misma con la memoria del receptor. 


\section{8}

Tenemos, por consiguiente, que desde el contexto de la comunicación la información debe considerarse a tres niveles distintos que corresponden a tres problemas técnicos diferentes de comunicación: 1) el problema de los signos o señales y el de su transmisión correcta; 2) el problema del significado tanto a nivel de diccionario como a nivel referencial; 3) el problema de la efectividad de la comunicación o de la eficacia de la misma sobre el receptor. En psicología, Skinner enfoca el tema de la comunicación desde el tercer nivel o pragmática, Fodor lo enfoca desde el segundo nivel y específicamente como problema referencial (Tous, 1978), mientras que Chomsky representa el segundo nivel desde el punto de vista estrictamente lingüistico, y Shannon el primer nivel o sintaxis.

Una paradoja interesante es la que puso de manifiesto Turner (1977) al encontrar mediante un estudio sociológico que la comunicación mediante los medios sociales de los desastres que ocurren en el mundo servía inicialmente más para aumentar la incertidumbre en los receptores que para disminuirla. Parecia pues que mientras a nivel sintáctico la presencia de la señal reducía la incertidumbre a nivel semántico se daba un aumento de la incertidumbre. Para analizar esta contradicción Turner acude a la distinción realizada por Cherry entre canales de comunicación y canales de observación. Para Collin Cherry no es lo mismo extraer información de la realidad misma que utilizar la información extraída para cambiar nuestros modelos o representaciones de la realidad, basados en la teoría de la comunicación y, por consiguiente, ajenos o exteriores a la misma naturaleza. En el primer caso utilizamos un canal de observación (por ejemplo, el microscopio), en el segundo caso un canal de comunicación (por ejemplo, un teléfono).

Según Turner, la diferencia entre el canal de comunicación y el canal de observación consiste en que el primero dispone de una serie de categorías preesta- blecidas y pensadas para transmitir y recibir, las cuales pueden ser utilizadas para la comunicación de los mensajes, mientras que el canal de observación no dispone de una serie limitada de categorías «a priori»; por lo que el canal de comunicación lo considera como un sistema cerrado y en cambio el canal de observación como un sistema abierto. Para Turner, además, la definición de la información como reducción de la incertidumbre está asociada con el emisor y no con el receptor en la teoría propuesta por Cherry, por lo que entiende que el emisor es primero un observador para poder ser posteriormente un emisor. Lo que realmente está haciendo el emisor es pasar del canal de observación al canal de comunicación consiguiendo que con cada nueva observación se produzca una reducción de la incertidumbre.

Esta generalización de la reducción de la incertidumbre desde el canal de observación al canal de comunicación Turner la plantea mediante la presencia de un cambio o discontinuidad del contexto de información nuevo. Dado un contexto conocido existe en el mismo un determinado nivel de reducción de la incertidumbre o certidumbre propio de este contexto, pero el incremento de la reducción de la incertidumbre en el mismo está limitado, ya que cada contexto tiende a excluir aquella información que resulta discrepante con el mismo tratándola como un error. Esta explicación de la limitación de la reducción de la incertidumbre podemos entenderla como una inercia social que influye en la actividad perceptual evitando que aparezcan anomalías o contradicciones en un contexto dado. Cuando ocurre un suceso nuevo, inesperado e inexplicable en aquel contexto, se produce un cambio discontinuo que da como resultado la aparición de un contexto nuevo y distinto del anterior porque en él pueden asimilarse lo que anteriormente era discrepante o contradictorio. Es en este nuevo contexto que proseguirá la reducción de la incertidumbre que había quedado limitada en el contexto anterior. 
Este paso de un contexto a otro no podría darse en una comunicación donde el papel del receptor tiene un carácter totalmente pasivo. Para que el emisor pueda pasar de un contexto a otro hemos visto que era necesario que estuviese actuando de observador, del mismo modo para que la comunicación que recibe el receptor sea información capaz por tanto de reducir su incertidumbre, el receptor debe actuar de observador. El receptor debe tratar el canal de comunicación como un canal de observación.

\section{LA INFORMACION DESDE LA CIBERNETICA}

De nuestro planteamiento anterior se desprende que la información debe considerarse desde tres puntos de vista distintos, pero interdependientes, que son el sintáctico, el semántico y el pragmático. También explicitamos que la información no es un problema del significado, sino un problema de la referencia, lo cual quedó de manifiesto al demostrar que la información se da en los canales de observación. Hemos tomado, además de Turner, la distinción entre sistema cerrado y abierto que ahora nos servirá para introducirnos en el contexto de la cibernética y la teoría de sistema.

Partimos de la suposición generalmente aceptada de que no es lo mismo hablar de información en un sistema físico que hablar de información en un sistema general. En los sistemas físicos, el estado del sistema es fácilmente reversible $\mathrm{y}$ esto hace que sean considerados sistemas cerrados, mientras que los sistemas biológicos y humanos el estado del sistema es evolutivo y apenas reversible por lo que se consideran sistemas abiertos. Queda por tanto explícito que Turner modeliza el canal de comunicación como un sistema físico y modeliza el canal de observación como un sistema biológico. Además ha quedado implícito que la medida de la información establecida a nivel sintáctico por la teoría estadística de la comunicación no puede generalizarse ni a nivel semántico, ni a nivel pragmático.

De la existencia de estos tres niveles de comunicación podemos presuponer la existencia de tres objetos de estudio diferentes respecto a la información: para unos la información es un dato que elabora el emisor y recibe el receptor; para otros la información es el contenido de un mensaje capaz de producir efecto en el receptor; para otros la información es simplemente la modificación producida en el receptor. Fernand E. Mairlot (1977) concluye de este análisis que desde el punto de vista lógico en el primer caso la información se considera como una causa, ya que se sitúa anterior a la comunicación. En el segundo caso, la información se considera como la consecuencia de la comunicación, ya que se sitúa en el receptor. En el tercer caso, la información se contempla como el resultado de la misma en el receptor, ya que se plantea como el proceso por el cual un estado del sistema receptor se transforma en otro estado. Para Mairlot sólo el tercer caso nos da una descripción adecuada del concepto de información, ya que si acudimos a la etimología de la palabra información veremos que se trata de la denominación de la acción de transformar una forma en otra: (sustantivo: informatio, verbo: informare), de este modo las otras dos maneras de definir la información no son más que aspectos derivados de esta definición en el primer caso como capacidad potencial y en el segundo como capacidad actualizada.

De este planteamiento se hace explícito que la información debe considerarse tanto expresión como recepción y que no puede hablarse de información sin un sistema capaz de producirla y un sistema capaz de recibirla. Shannon, en su teoría, se planteó fundamentalmente el problema de la recepción de la información, ya que consideró que la cantidad de información contenida en un mensaje está estrechamente ligada a la sintaxis de este mensaje; pero es fácil constatar que un mismo mensaje es percibido de distinta 
forma por dos receptores distintos $\mathrm{y}$, por consiguiente, que la cantidad de información contenida en un mensaje está también estrechamente ligada a la semántica de este mensaje. Podemos distinguir por tanto entre un concepto absoluto de información y un concepto relativista de información. Además, también podemos distinguir que la información como expresión consiste en un significado, mientras que la información como recepción adquiere una dimensión referencial. Esto implica aceptar que la información tiene una dualidad sintáctico-semántica que Mairlot formaliza del siguiente modo:

1. Un sistema (S) considerado como una parte arbitrariamente separada de un Universo (U), y definido por relación a un observador (R), como algo que dispone de una estructura invariante.

2. Este mismo sistema que recibe información proveniente de su medio (o todo aquello que no es el mismo) y que utiliza esta información para modificar su estructura interna de forma que pueda conseguir cierto objetivo.

3. El medio debe considerarse ciego en el sentido de que no puede observar su propia evolución o cambio de su estructura interna.

4. El sistema así considerado sí puede observar su propia evolución ya que su estado (negentropía) representa la cantidad total de información acumulada en un momento $y$, por consiguiente, el conocimiento que el sistema tiene de su medio.

5. Principio de la evolución: Este tipo de sistema evoluciona hasta maximizar la variación entre su estado pasado y futuro gracias a la información que alcanza de su medio.

De estos principios se sigue que los sistemas generales o sea que incluyen tanto a los sistemas cerrados como abiertos se pueden describir mediante las siguientes variables:

A) Entropia interna (Hi): consiste en un parámetro cuantitativo que representa la organización de los subsistemas y elementos que constituyen el sistema.

B) Entropía externa (Ho): consiste en el conocimiento que el sistema tiene de la estructura interna de su medio, en la medida que un observador ( $R$ ) pueda estimar esta cantidad.

C) Objetivo del sistema: puede ser cuantitativo: minimizar una función, puede ser topológico: cerrado-abierto (retroalimentación positiva), puede ser constante como la supervivencia (retroalimentación negativa).

D) Potencial del sistema: representa la inercia del sistema así considerado ante toda posible variación de su propia estructura interna. Podemos operacionarlo como un factor de cohesión interna.

Esta tímida presentación de la reconstrucción teórica realizada por Mairlot establece por una parte una nueva perspectiva a la lingüística matemática y por otra, que es la que yo he tomado en consideración aqui, nos permite modelizar la comunicación en base a las siguientes identificaciones:

(S) Sistema observado: La frase o mensaje que se da en la comunicación.

Hi) Entropía interna de (S): consiste en la sintaxis del mensaje.

Ho) Entropía externa de (S): consiste en la semántica (referencia) del mensaje.

R) Observador directo de la realidad: es el emisor del mensaje.

$\left.R^{\prime}\right)$ Observador indirecto de la realidad: es el receptor del mensaje.

La aplicación de este modelo relativista de información comporta considerar que el emisor actúa de intermediario, en el acto de la comunicación, entre su observación y la elaboración del mensaje, por lo que el receptor del mismo recibe tanto una información basada en la estructura interna del mensaje, como una información basada en la estructura externa del mensaje. Tenemos pues, que tanto en el receptor como en el emisor el 
mensaje tiene dos componentes de información: el interno que corresponde a un código determinado de comunicación $y$, por consiguiente, es cerrado (sintaxis) y el externo que corresponde en el caso del emisor a la observación directa y en el caso del receptor a la observación indirecta o al hecho de haber convertido en canal de observación el canal de comunicación.

Para poder defender el modelo propuesto como un sistema abierto realmente referente de un sistema real debemos introducir los conceptos de invariante, de energía y la relación del concepto de semántica ya expuesto con el concepto de energía. El invariante según Dubois (1978) representa la referencia de base que nos permite extraer los principios fundamentales de la realidad observada, se trata del estado de la estructura de un sistema en un momento dado. La energía es la fuerza necesaria para modificar su estado un sistema, por lo que entonces la semántica podría considerarse como el signo o la dirección del cambio de estado del sistema gracias a su energía. Es tan estrecha la relación entre energía y semántica que estos autores consideran necesario elaborar un nuevo concepto que por sí sólo abarque todos los aspectos referentes al cambio del estado del sistema. Este concepto Mairlot lo denominó: ENERSEAN y nos lo delimita del siguiente modo:

"La información no es materia ni energía, ni mensaje; sino el proceso mismo de transformación del estado de un sistema en otro estado diferente del anterior. La modificación de un estado es posible por el impacto de la comunicación que viene asegurada por la transmisión de energía liberada por el emisor y que el receptor es capaz de integrar. Los estados del emisor y del receptor se ven asi modificados por estos procesos de liberación e integración.»

Para que esta energía débil sea operativà fijémonos que debe poder ser inte- grada por el receptor, es decir, que esta energía debe ser ella misma información. Mairlot nos dice al respecto: "Para que la energía sea un factor de información es indispensable que exista una relación entre su forma y la estructura del receptor». Por lo que vemos que la información está ligada a la acción fisica responsable de un cambio en la forma de la estructura o estado del receptor.

El planteamiento que hemos propuesto es, obviamente, aplicable al ser humano si tomamos en consideración del mismo los diferentes tipos de conducta que mánifiesta. Al referirnos al ser humano podemos decir del mismo que tiene una conducta refleja, una conducta aprendida y una conducta mental. La distinción entre estos diferentes tipos de conducta podemos basarla como expuso Montserrat Esteve (1982) en tres patrones básicos y distintos:

A) Un patrón heredado con retroalimentación negativa y base material objetiva que opera en el tiempo real como reactor para comparar. Se trata de un patrón genotípico cuyo modelo consiste en el reflejo absoluto.

B) Un patrón adquirido con retroalimentación negativa y positiva que opera en el tiempo subjetivo como reactor para comparar. Se trata de un patrón fenotípico cuyo modelo consiste en el reflejo condicionado.

C) Un patrón imaginario o imaginado con retroalimentación positiva que opera en el tiempo virtual como reactor para comparar. Se trata de un patrón fenotípico cuyo modelo consiste en el reflejo extrapolacional.

Una característica importante de estos patrones es que gobiernan provisionalmente, cuando está presente la información material, o sea, aquella cuya energia y semántica son unívocas y estables se da el primer patrón y la comparación se realiza mediante el control homeostático. De estar presente la información temporal-espacial, o sea, aquella cuya energía no es univoca con su semántica, ya que 
ésta va cambiando en el espacio y tiempo, se manifiesta el segundo patrón y la comparación se lleva a cabo mediante el llamado control anticipatorio. $\mathrm{Si}$ está presente la información virtual (Ciplea, 1982), o sea aquella cuya energía no es univoca con su semántica, porque ésta es de carácter representacional se da el tercer patrón y la comparación se realiza mediante la autodeterminación.

Estos tres tipos de patrones encuentran su formalización como sistemas en la obra de Bush, G. A. (1979). Según este autor los sistemas pueden clasificarse en cerrados y abiertos, atendiendo a su tendencia al cero absoluto los primeros o sistemas entrópicos, atribuyendo a los segundos el mantenimiento de un determinado nivel de entropía o sistemas negentrópicos. Dentro de los sistemas abiertos es necesario además distinguir con fines de clasificación entre sistemas abiertos morfoestáticos y sistemas abiertos morfogénicos. Constituyen los sistemas abiertos morfoestéticos aquellos cuya forma de control es homoestática, mientras que los sistemas abiertos morfogénicos son aquellos cuya forma de control es anamórfica. La actividad de los sistemas morfoestáticos no cambia la forma de la estructura de los mismos, en cambio la actividad de los sistemas morfogénicos produce cambios en la forma de la estructura de los mismos. Además, podemos distinguir en los sistemas abiertos morfogénicos, aquellos que operan con signos de aquellos que operan con símbolos; por causa de la mayor flexibilidad o labilidad de estos últimos.

La retroalimentación en los sistemas abiertos morfoestáticos es negativa $y$ funciona mediante el control de señales de un repertorio fijo. Trata por consiguiente con información material, correspondiendo al nivel sintáctico en cuanto a su significado y a los reflejos absolutos de Paulov. La retroalimentación, en los sistemas abiertos morfogénicos es negativa y positiva y funciona mediante el control de signos, propios de un repertorio variable, correspondiendo al nivel semántico referencial en cuanto a su significado y a los reflejos condicionados o aprendizaje. En este caso el sistema es anamórfico, pero de alteración o cambio limitado, mientras que cuando la retroalimentación es positiva y negativa en los sistemas abiertos morfogénicos y funciona mediante el control de símbolos, correspondiente al nivel semántico virtual en cuanto a su significado y a los reflejos extrapolacionales o autodeterminación.

Hablar de retroalimentación positiva y negativa al referimos a los sistemas abiertos morfogénicos tiene un cierto riesgo, ya que se considera que la retroalimentación debe ser necesariamente negativa para evitar la destrucción del sistema. Esta apreciación está justificada en el caso de los sistemas abiertos o negentrópicos de carácter morfoestático, ya que éstos no pueden modificar la forma de su estructura; pero en aquellos sistemas abiertos o negentrópicos de carácter morfogénico es posible la modificación de la forma de su propia estructura. Tomemos el caso del proceso de un gusano a crisálida y a mariposa, en este ejemplo la estructura cambia de forma en cada nuevo estadio y, por tanto, podemos hablar de retroalimentación simplemente positiva. Tomando de nuevo la proposición de B. A. Turner, cuando el estado A de una estructura resulta incapacitado para integrar la nueva información pasa de modo discontinuo a un estado $\mathrm{B}$ distinto, lo cual representa un cambio en el orden interno de la estructura, o sea en su forma. A partir de los resultados encontrados hasta el presente en el campo de la deficiencia mental (Ellis, 1982), parece plausible hipotetizar la relación entre los procesos seriales y la retroalimentación negativa y la relación entre los procesos de control y la retroalimentación positiva (Tous, 1984). Por último, consideramos que cada uno de estos tres sistemas no constituyen más que tres subsistemas del sistema complejo, objeto de nuestro estudio que denominamos ser humano. 


\section{Estudios}

\section{Referencias}

Ackoff, R. L.: "Science in the Systems Age: Beyond IE,OR and MS», Operational Rescarch, 1973, 21,661 671.

ARNAU, J.: "La explicación en psicología experimental; del conductismo al cognitivismo (una alternativa paradigmática)m. En: Psicologia cognitiva y procesamiento de la información, Delclaux, I. y Seoane, J., Pirámide, Madrid, 1982.

Bush, G. A.: «Cybernetics IIl System-Type Applicable to human beings». Cybernetica, 1979, Vol. XXII, n.' 2, 89-101.

BoulangkR, G. R.: «Cybernetique», Cybernetica, 1981, Vol. XXIV, n. ${ }^{\circ} 3,173-190$.

ChERry, C.: On buman communication. A review, a survey, and a criticism. The M.I.T. Press. Massachussetts, Cambridge, 1956.

CipleA, L. J.: «The Virtual Information. Cybernética, 1982, Vol. XXV, n. ${ }^{\circ}$ 1, 17-25.

Clausius en: Historia de la Humanidad, Charles Morazé, 1859-1865, Tomo 7, 169-170.

DuBols: «Symposium sur divers aspect du concept d'information», Cybernética, 1977, Vol. XX, n. ${ }^{\circ} 1,5-38$.

ElliS, N. R.: Investigatión en retraso mental, Edita Servicio Internacional de Información sobre Subnormales, San Sebastián, 1982.

FoDor, J. A.: The Modularity of Mind, The MIT Press, Cambridge, 1983.

GARreT, MERril, en: The modularity of Mind, de J. A. Fodor. The MIT Press, Cambridge, 1983.

GONZÁlez P.: «Ánálisis bibliométrico de la memoria semántica». Tesis de Licenciatura no publicada. U. de Barcelona, 1984 (dir. Antonio Caparrós y José M. ${ }^{2}$ Tous).

Hintman, D. L.: The Psychology of Learning and Memory, W. H. Freeman and Company, San Francisco, 1978.

Lachman, R.; Lachman, S. L., y Butterfield, E. C.: Cognitive Psychology and Information Processing. Lawrence Erlbaum Associates, Inc. Publishers, 1979.

MahONEY, M. J.: Cognition and behavior Modification; Cambridge, Massachussetts, Bellinger, 1974.

MaIrlot, F. E.: «Symposium sur divers aspects du concept d'information». Cybernética, 1977, Vol. XX, n." $1,5-38$.

Miller, G. A., Galantier, E., y Pribam, K. H.: Plans and the structure of bebavior, Holt, Rinehart and Winston, New York, 1960.

Montserrat. Esteve, S.: "La equilibración de las estructuras cognitivas de J. Piaget desde un enfoque cibernéticom. Ponencia presentada al Seminario de Pedagogia, Cibernética y Ciencias Sociales organizado por el Dto. de Pedagogía Sistemática de la Facultad de Filosofia y Ciencias de la Educación de la Universidad de Barcelona, 1982.

Navarro Martín: Manual de Psicologia Experimental. Imprenta Pijoan, Tarragona, 1914.

NeISSER, U.: Psicología cognoscitiva, Trillas, México, 1976 (original: 1967).

OGDEN, C. K., y RichARDS, I. A.: The meaning of meaning, Routledge and kegan Paul Ltd. London, 1949.

Osgood, CH. E., Suci, G. J., y TANnenbaum, P. H.: The measure of meaning. University of Illinois Press, 1957.

PeIRCE, C. S.: Collected Papers of Charles Sanders Peirce, Harverd University Press, Cambridge, 1931-1935.

REMESAR A., RiBA, C., y Rodriguez, J. L.: Tres ensayos sobre comunicación, de la naturaleqa a la cultura, Ediciones Marcaron, Barcelona, 1982.

Tous Ral, J. M.: Psicologia Experimental, problemas de teória y método. Ediciones Omega, Barcelona, 1978.

TOUS RAL, J. M.': Psicologia Informacional. Una introducción a la psicología teórica. Promociones Publicaciones Universitarias, Barcelona, en prensa.

Tous J. M.", y VALLEjo, G.: «El significado en la rememorización libre de material verbal». Anuario de Psicologia, $1980(1), 51-57$.

TURNER, B. A. Research Note: «A comment on the Nature of Information in Channels of Observation», Cybernética, 1977, Vol. XX, n.* 1.

VALLEjo, G.: «Memoria episódica y memoria semántica». Universitas Tarraconensis, en prensa. 